Supporting Information

\title{
Understanding the thermal denaturation of myoglobin with IMS-MS: evidence for multiple stable structures and trapped pre-equilibrium states
}

Daniel W. Woodall, ${ }^{a}$ Lucas W. Henderson, ${ }^{a}$ Shannon A. Raab, ${ }^{a}$ Kenji Honma, ${ }^{\text {b }}$ and David E. Clemmer ${ }^{\mathrm{a}, *}$

${ }^{a}$ Department of Chemistry, Indiana University, Bloomington, Indiana, 47405

${ }^{b}$ Graduate School of Material Science, University of Hyogo, 3-2-1 Kohto, Kamigori, Hyogo 678-1297, Japan

*Corresponding author:

David E. Clemmer 
a.

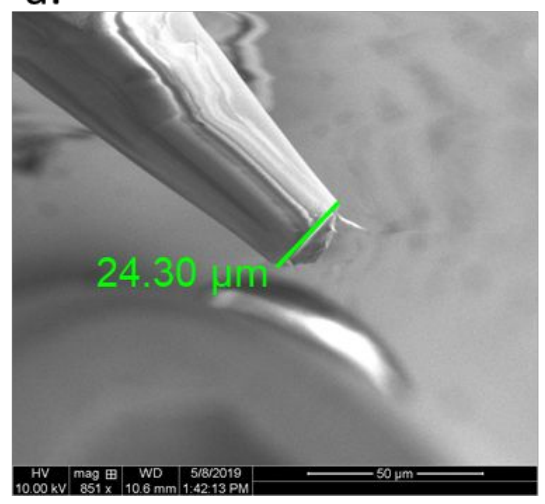

b

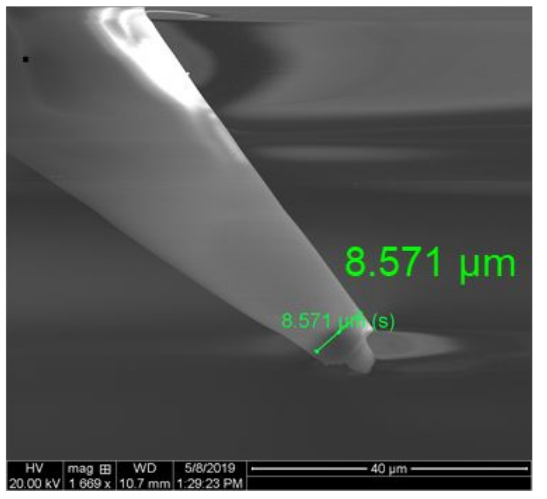

c.

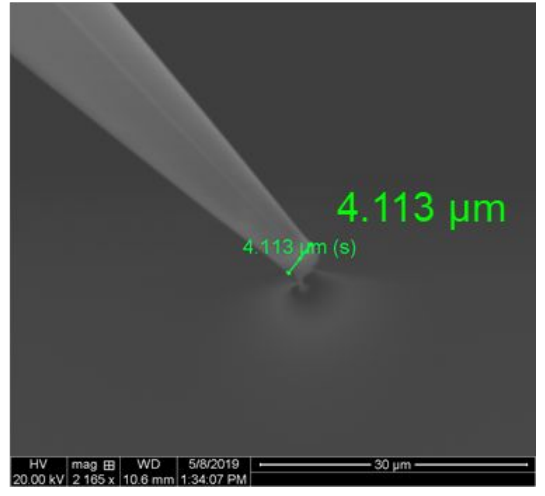

Figure S1. Scanning electron microscopy images of ESI capillary tips used in laser droplet heating experiments. Three different tip sizes were used, having diameters of $24.3 \mu \mathrm{m}$ (a.), 8.60 $\mu \mathrm{m}$ (b.), and $4.10 \mu \mathrm{m}$ (c.). 


\section{$45^{\circ} \mathrm{C}$}

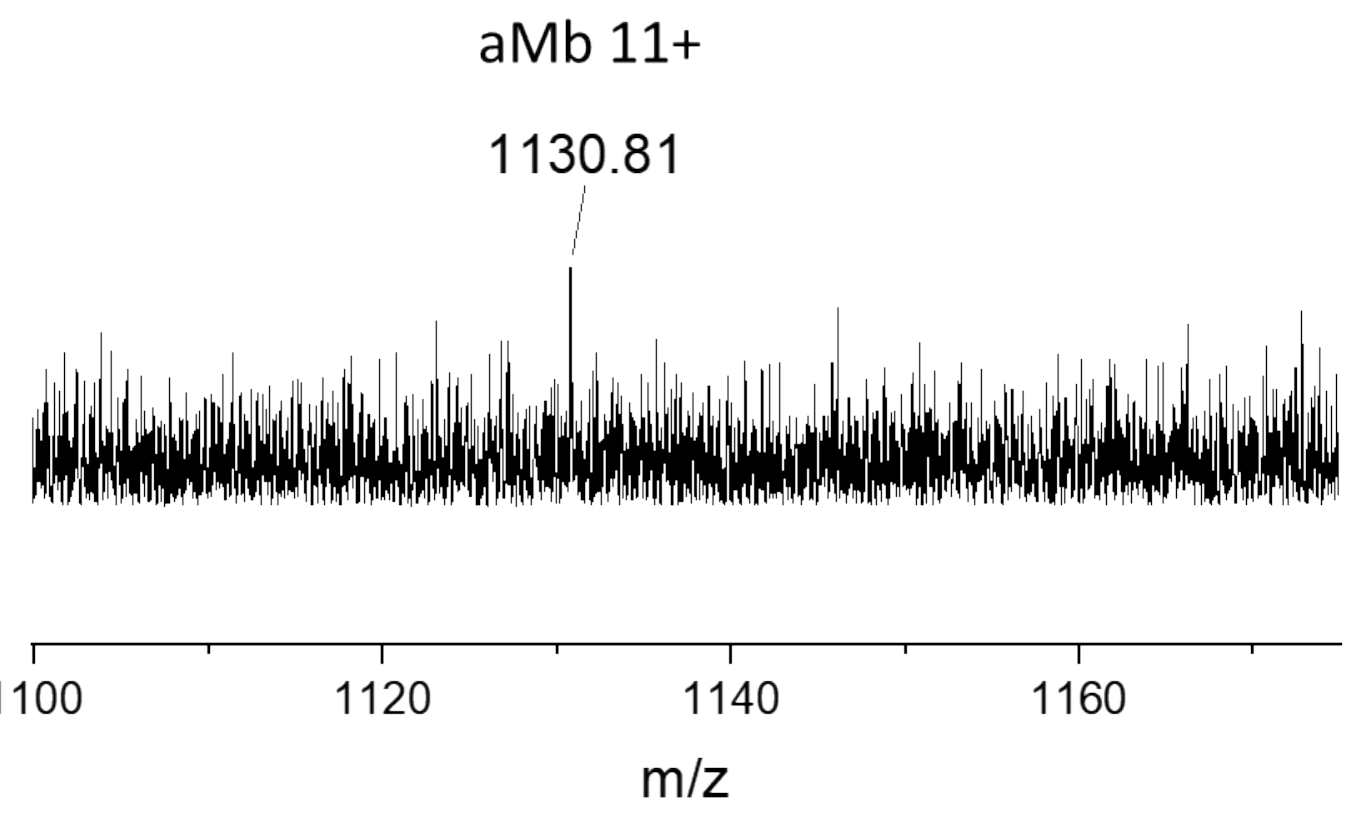

Figure S2. Zoomed mass spectra of holomyoglobin acquired at a solution temperature $45{ }^{\circ} \mathrm{C}$ in $\mathrm{pH}=9.0$ ammonium acetate. Peaks corresponding to apomyoglobin ( $\mathrm{aMb}$ ) begin to appear in the mass spectrum at temperatures above $45^{\circ} \mathrm{C}$. The $11+\mathrm{aMb}$ species is annotated in the mass spectrum. 
hMb 8+

\section{Solution heating}

$6 \mathrm{~V}$ collision energy

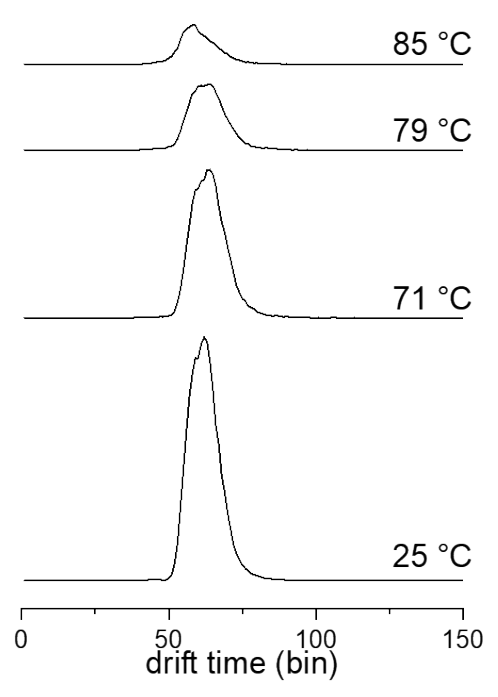

Laser droplet heating

$6 \mathrm{~V}$ collision energy

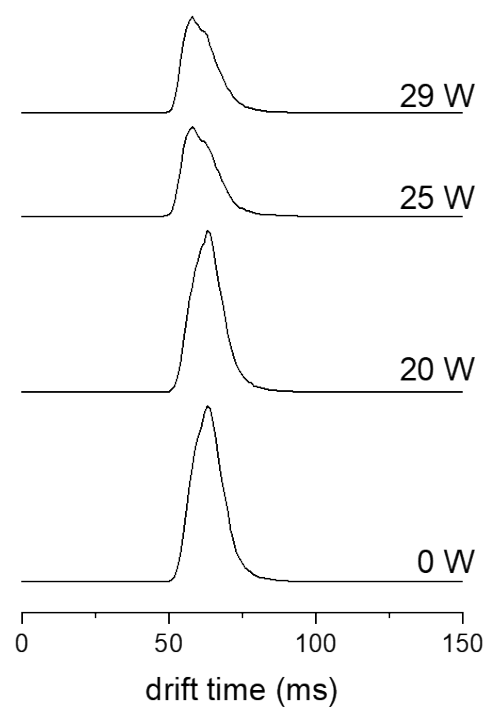

Laser + collisional activation

$25 \mathrm{~W}$ laser power

stable gas-phase conformers

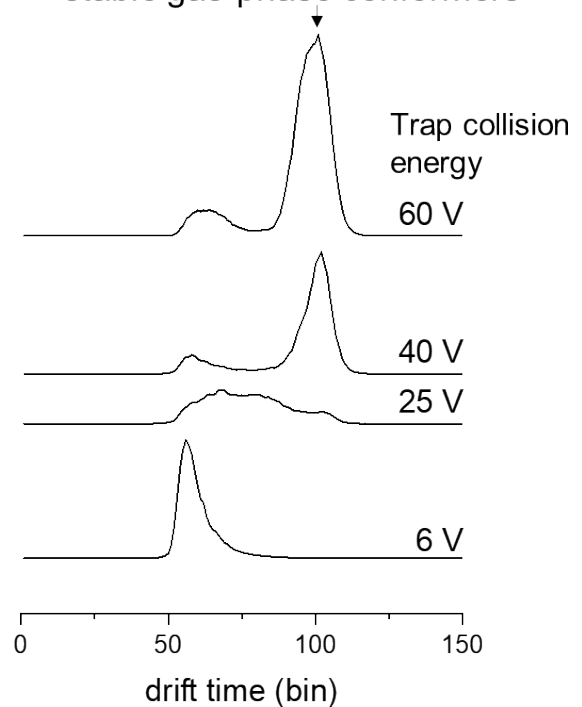

Figure S3. Drift time distributions of $\mathrm{hMb} 8+$ ions at increasing temperatures $(25,71,79$, and 85 ${ }^{\circ} \mathrm{C}$ (left)), laser power $(0,20,25,29 \mathrm{~W}$ (middle)) and collisional activation 6, 25, 40, and $60 \mathrm{~V}$ (right)). All samples were prepared in $10 \mathrm{mM}$ ammonium acetate $(\mathrm{pH}=9)$, and electrosprayed from $\sim 8 \mu \mathrm{m}$ emitters. 


\section{Solution heating}

$6 \mathrm{~V}$ collision energy

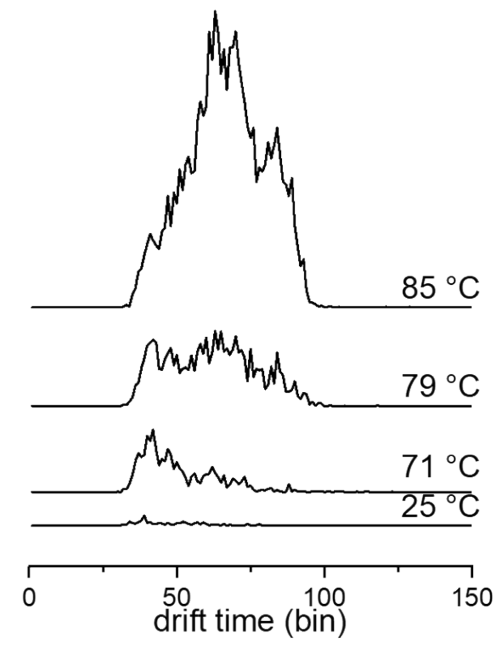

hMb 11+

\section{Laser droplet heating}

$6 \mathrm{~V}$ collision energy

\section{Laser + collisional activation} $25 \mathrm{~W}$ laser power stable gas-phase conformers

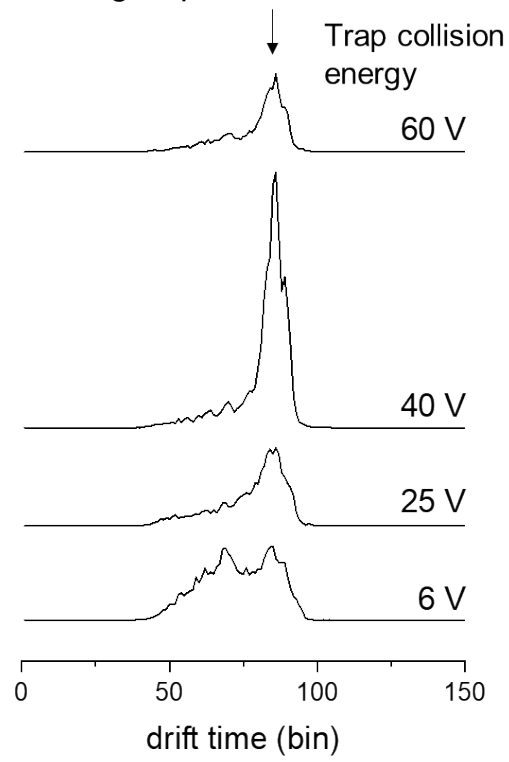

Figure S4. Drift time distributions of $\mathrm{hMb} 11+$ ions at increasing temperatures $(25,71,79$, and $85^{\circ} \mathrm{C}$ (left)), laser power $(0,20,25,29 \mathrm{~W}$ (middle)) and collisional activation 6,25 , 40, and 60 $\mathrm{V}$ (right)). All samples were prepared in $10 \mathrm{mM}$ ammonium acetate $(\mathrm{pH}=9)$, and electrosprayed from $\sim 8 \mu \mathrm{m}$ emitters. 
hMb 13+

\section{Solution heating}

$6 \mathrm{~V}$ collision energy

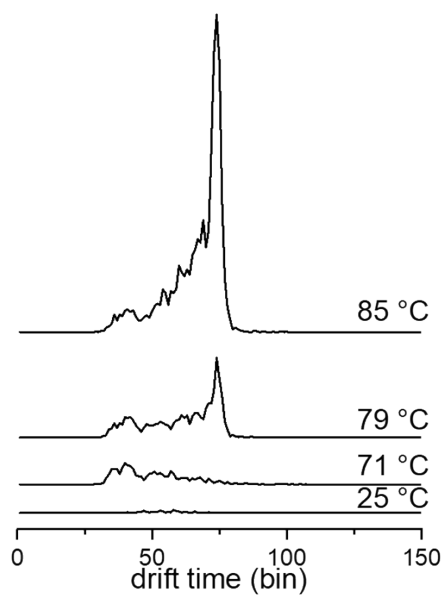

$6 \mathrm{~V}$ collision energy
Laser droplet heating

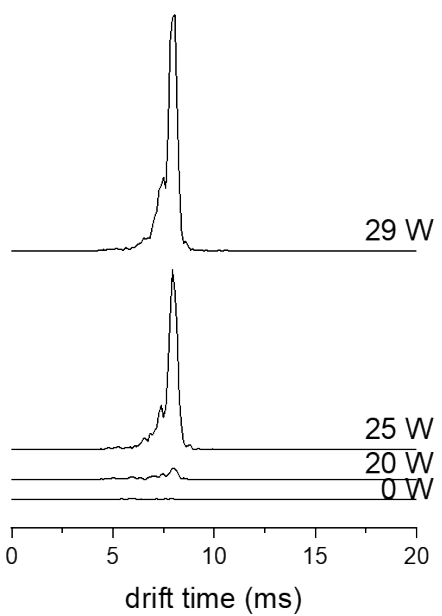

Laser + collisional activation

$25 \mathrm{~W}$ laser power

Trap collision energy

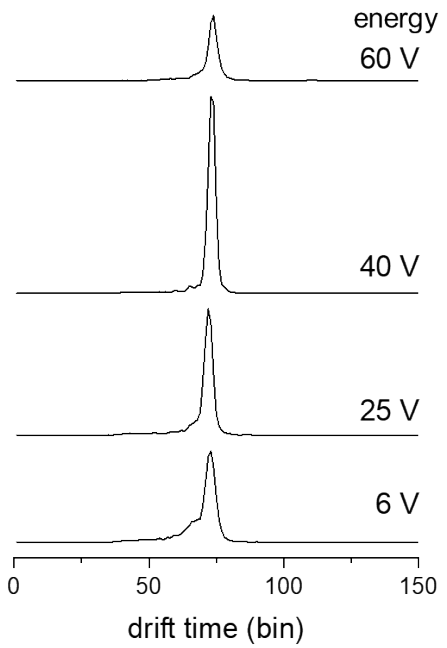

Figure S5. Drift time distributions of $\mathrm{hMb} 13+$ ions at increasing temperatures $(25,71,79$, and $85^{\circ} \mathrm{C}$ (left)), laser power $(0,20,25,29 \mathrm{~W}$ (middle)) and collisional activation 6, 25, 40, and 60 $\mathrm{V}$ (right)). All samples were prepared in $10 \mathrm{mM}$ ammonium acetate $(\mathrm{pH}=9)$, and electrosprayed from $\sim 8 \mu \mathrm{m}$ emitters. 